\title{
UTILIZATION OF ROSMARIN LEAF OIL (Rosmarinus officinalis L) ON Culex Quinquefasciatus MOSQUITO LARVA AS A FILARIASIS VECTOR (ELEPHANT FOOT DISEASE)
}

\author{
Dyah Susilowati \\ D3 Farmasi, Poltekkes Bhakti Mulia Sukoharjo \\ Corresponding author : Susilowatidyah75@gmail.com
}

\begin{abstract}
Elephantiasis (filariasis / elephantiasis) is still endemic in hundreds of districts in Indonesia and has become a health problem for the world community in accordance with the resolution of the World Health Assembly (WHA) in 1997. This is caused by Culex quinquefasciatus mosquitoes as one of many filariasis vectors found in urban areas (Gandahusada et al., 1998), while the number of filariasis chronic cases reported until 2009 was 11,914 cases. Filariasis / elephantiasisi is a chronic infectious disease caused by filarial worm infection transmitted by various types of mosquitoes in the lymph nodes, this disease is chronic (chronic) and if it does not get treatment can cause permanent disability in the form of enlargement of the legs, arms and genitals both women and men man.

Rosmarin (Rosmarinus officinalis L.) is a multifunctional plant in Indonesia especially abroad, one of its benefits is as larvicides. Because rosmarin has a chemical compound, one of them is essential oil which has larvicidal effectiveness on Culex quinquefasciatus mosquito larvae as vector filariasis (elephantiasis) Essential oil was obtained by distillation of fresh rosmarin leaves, then each extract was made with $1000 \mathrm{ppm}$ stock solution and then made 6 series of concentration of $12.5 \mathrm{ppm}$ to $300 \mathrm{ppm}$ then tested on 20 larvae of instar III Culex quinquefasciatus, Observations were made after 24 hours and calculated LC90 uses an analysis of the orbit.

The results obtained were only essential oils of Rosmarin leaves (Rosmarinus officinalis L.) which had larvicidal activity against Culex quinquefasciatus mosquito larvae, with LC90 182,9756 ppm.
\end{abstract}

Keywoard: essential oil, rosmarin, Culex quinquefasciatus, filariasis,

\section{Introduction}

Elephantiasis (filariasis / elephantiasis) is still endemic in hundreds of regencies in Indonesia due to Culex quinquefasciatus mosquitoes as filariasis vectors found in urban areas (Gandahusada et al., 1998). One of the efforts taken to prevent mosquito-borne diseases is using insecticides. But synthetic insecticides have negative impacts, among others, environmental pollution, predator death, resistance of target insects, can kill pets, even humans (Susanna et al. , 1999) In connection with this, it is necessary to make an effort to obtain natural insecticides derived from chemical compounds contained in plants, so that we try to test the effectiveness of larvicides using rosmarin. The purpose of using rosmarin as an insecticide (larvacide) is to find natural insecticides with the content of active compounds in it so that it is expected to have a contribution in killing Culex quinquefasciatus mosquitoes as filariasis vectors (elephantiasis).

\section{Methods}

A. Research Stages

1. Determination of plants in this research phase is to determine the correctness of a sample of rosmarin plant (Rosmarinus 
officinalis L.) which is related to its characteristics and morphology with plant determination instructions conducted at the Laboratory of the Center for Research and Development of Traditional Medicinal and Medicinal Plants (B2P2TO2T) in Tawangmangu area, Karanganyar.

2. Material collection

Rosmarin leaves that are young and fresh, which have been separated from the trunk, are taken from the Tawangmangu, Karanganyar area.

3. Water distillation

Rosmarin leaves 100 grams for one time refining. The material is put into a $1000 \mathrm{ml}$ distillation flask, then added with $500 \mathrm{ml}$ aquadestilata until the sample is submerged and connected with a kjedahl tube and filled with water then connected with a condenser (cooler) mounted upright. After the appliance is installed, then heated to boiling and moisture rises. Distillation lasts for 5 hours and then 30 minutes is added to see that the essential oil really does not drip again, then observed the volume of essential oil that is distilled. The oil obtained is added with sodium sulfate to remove water. The oil obtained is then stored in a brown bottle and filled full, tightly closed and protected by light.

4. Test for larvicidal activity

Approximately 42 containers were used for the test media for 6 series of sample concentrations tested, 12.5 ppm, 25 ppm, 50 ppm, 100 ppm, 200 ppm and 300 ppm, along with abate as a positive control, aquadest as a negative control for each sample for two types of mosquito larvae. The volume of each test media was 80 $\mathrm{ml}$ with 20 instar larvae of Culex quinquefasciatus mosquitoes. Each concentration of essential oil is tested with repetition 3 times.

Larval mortality can be observed after 24 hours after treatment by calculating the percentage of larval mortality.

5. Analysis Method

Determination of LC90. The number of larvae of Culex quinquefasciatus that died after the treatment was determined by the death rate. Culex quinquefasciatus mosquito larvae are then searched for probit by using probit conversion table, after the probit value is known for each concentration then a relationship curve is made between log concentration $(\mathrm{X})$ and probit $(\mathrm{Y})$ value which is Volume 1 Issue 1 (2018) a linear relationship with a straight line $\mathrm{Y}=\mathrm{a}+$ bx. After that, the LC90 price is calculated from the equation $\mathrm{Y}=\mathrm{a}+\mathrm{bx}$ by entering the probit value of $90 \%$ of the death of the test animal as $(\mathrm{Y})$, then the antilog will be obtained $(\mathrm{X})$ as the price of the LC90.

6. Category of larval condition after treatment Larvae that are considered dead when the larvae are given stimulation of the movement of water do not give a movement response, the larvae are touched with a stirring rod does not also provide a movement response. The larvae are considered alive when the active larvae move, the larvae live above the surface of the water by hanging to form an angle to the surface of the water, the larvae are given stimulation of the movement of water, giving a response to the movement and the larvae are touched with a stirring rod also provides a movement response.

7. Larvacide test scheme for essential oils, rosmarin leaves (Rosmarinus officinalis L.) on each Culex quinquefasciatus mosquito larvae

\section{Results And Discussion}

A. Research Results of Rosmarin Leaf Essential Oil

The average volatile oil content of rosmarin leaf obtained was $1.23 \% \mathrm{v} / \mathrm{b}$. Based on the data obtained, it can be seen that the content of rosmarin leaf essential oil according to the study was the same as the content of essential oils according to literature.

The examination results of the refractive index of rosmarin leaves. Refractive index checking is done with a refractometer and the results obtained by practice are 1.4700 at $28^{\circ} \mathrm{C}$, The result of determining the weight of the type of essential oil of rosmarin leaves. The weight of rosmarin leaf essential oil from this study was 0.938 at $28^{\circ} \mathrm{C}$.

B. Determination of Rosmarin Leaf (Rosmarinus officinalis L.)

Determination was carried out on plants studied according to the book Flora of Java written by C. A. Backer, so that the key to the determination of rosmarin leaves was obtained. The results of determination according to Backer are as follows: 1b_2b_3b_4b_12b_13b_14b_17b_18b_19b_20 b_21b_22b_23b_24b_25b_26b_27a_28b_29b_ 30b_31b_40bb277_28b_29b_30b_31b_403b_4 04b_405a_406b_409a_410b_411b_

190. Lamiaceae 
1b_2b_3a_4b 3. Rosmarinus

1 Rosmarinus officinalis $L$

The results of the determination can show that the plants used for the study are rosmarin plants which belong to the Lamiaceae family.

C. Larvicide Activity Test Results

The data obtained vary, in essential oils with a concentration of $25 \mathrm{ppm}$ the average mortality of larvae is 1 head. At a concentration of $50 \mathrm{ppm}$, the average mortality of larvae was 5 , and at a concentration of $100 \mathrm{ppm}$, the average mortality of larvae was 11 . While at a concentration of $200 \mathrm{ppm}$, the average mortality of larvae was 17, and starting from a concentration of 300 and above, the average mortality of larvae was 20. Positive control kills all larvae in the container, while the negative control does not kill the larvae.

Table 1. Test results of essential oils on mosquito larvae of Culex quinquifasciatus instar III (Attachment Table 1)

LC90 is a concentration that can kill or kill 90\% of test animals. In this study 3 values of LC90 were obtained, all of which were derived from replication of essential oils. In replication I obtained $149.5202 \mathrm{ppm}$, in replication II 214.4371 ppm, and replication III 184.9695 ppm. From the three data above, the average is calculated, and the result is $182.9756 \mathrm{ppm}$. This means that at a concentration of $182.9756 \mathrm{ppm}$ it can kill $90 \%$ of test animals. (Attachment : Figure $1,2,3,4)$

The results obtained above have a positive correlation between the number of larvae that die with concentration, meaning that if the concentration is increased, the number of dead larvae also increases. Variations in the concentration of essential oils that can reach $90 \%$ of larvae mortality so that the study can determine the LC90, it is evident that the essential oil of rosmarin leaves (Rosmarinus officialis L.) has larvicidal power against third instar Culex quinquefasciatus mosquitoes.

The results of the positive control showed the maximum value because it can kill all Culex quinquefasciatus larvae, while Tween 80 as a negative control did not affect the larval activity. This is evidenced by all the larvae in the negative control still alive.

\section{Conclusion}

Essential oils of rosmarin leaves (Rosmarinus officinalis L.) at a concentration of $182.9756 \mathrm{ppm}$ can kill 90\% of Culex quinquefasciatus mosquito larvae.

\section{References}

Agusta A. 2000. Indonesian Tropical Plant Essential Oils. Bandung: ITB

Anief. 2004. The Science of Making Drugs Theory and Practice. eleventh print. Yogyakarta: Gadjah Mada University Press.

Ansel HC. 1989. Introduction to Pharmaceutical Preparations, Edition IV. Jakarta: University of Indonesia.

Brotosisworo. $1978 . \quad$ Pharmacognosy. Yogyakarta: Faculty of Pharmacy, Universitas Gadjah Mada.

Bisset NG, Wichll M. 1994. Herbal Drugs and Phytopharmaceuticals, A Handbook for Practice on a Scientific Base. Stuttgart: CRC press, pp. 428-429.

Cahyani ENR. 2008. Effectiveness Test of Rosmarin Leaf Essential Oil in Lotion Preparation as Aedes aegity Mosquito Repelant. Surakarta: Setia Budi University.

Dewick, P.M. 1997. Medical Natural Products A Biosynthetic Approach. New York, USA: Jhon Wiley \& Sons.

Gandahusada S, Pribadi W, Illahue HD. 1998. Medical Parasitology Edition III. Jakarta: Faculty of Medicine, University of Indonesia.

Grieve M. A Modern herbal, http://www.botanical.com [19:58, 31 August 2010].

Gunawan D, Mulyani S. 2004. Natural Medicine (Pharmacognosy) Volume 1. Jakarta: Spreader self-help.

Harborne. 1987. Phytochemical Method, Modern Way Guide to Analyzing Plants, Bandung: ITB Publishers.

Hoan Jay T, Rahardja K. 2003. Important Medicines. Jakarta: PT Elex Media Komputindo, Gramedia, pp. 189-191.

Praeparandi. 1979. Analysis of Qualitative Pharmaceutical Chemicals. Bandung: Bandung Institute of Technology. 
Robinson T. 1995. Organic Plant High Content.

Padmawinanto $\mathrm{K}$, translator; Bandung:

ITB Press.

Soejoto, Soebari. 1996. Instructions on

Practicum on Medical Parasitology, Health

Attachment

Chart : Larvacide test scheme for essential oils, rosmarin leaves (Rosmarinus officinalis L.) on each Culex quinquefasciatus mosquito larvae

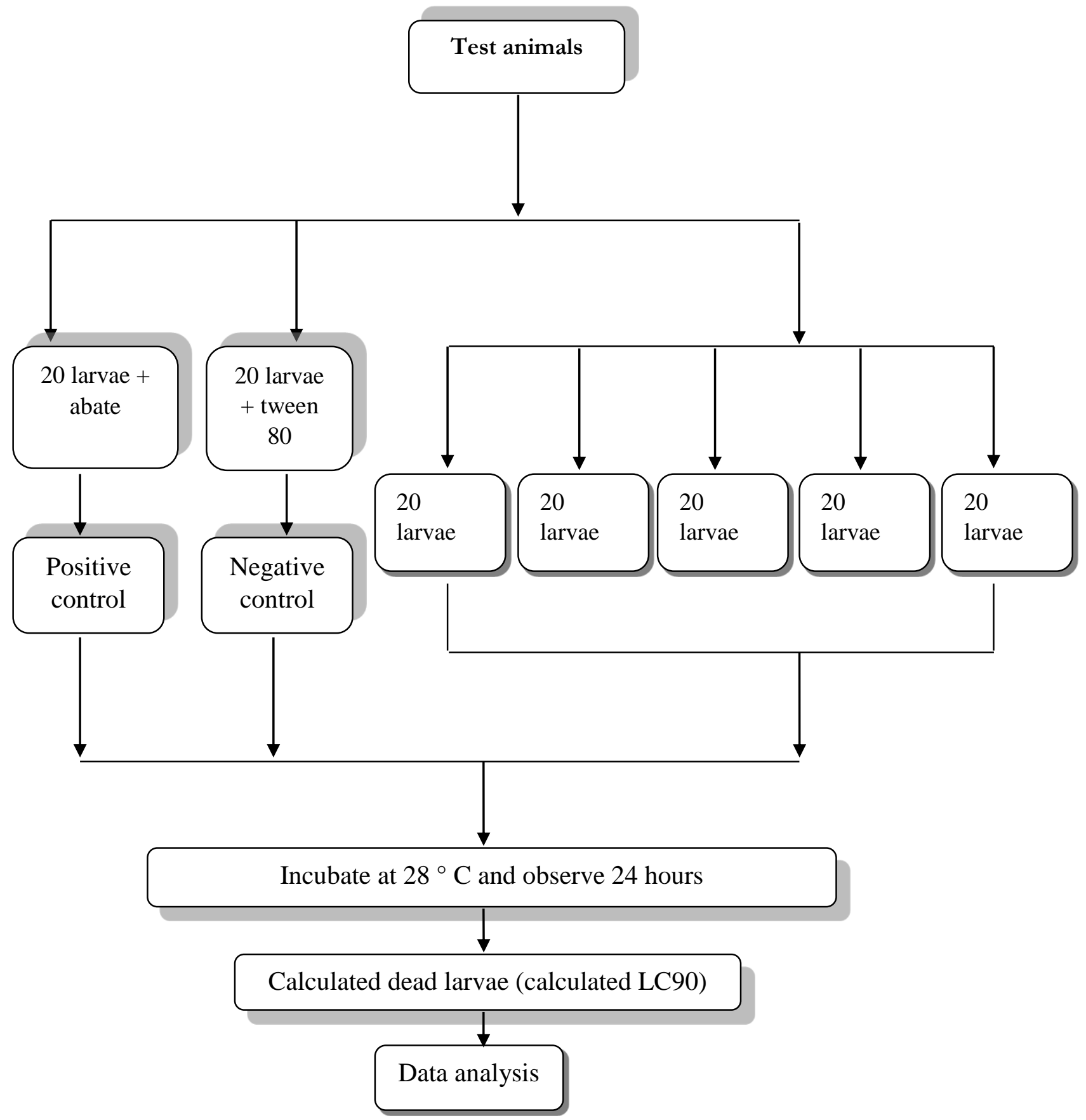


Table 1. Test results of essential oils on mosquito larvae of Culex quinquifasciatus instar III

\begin{tabular}{|c|c|c|c|c|}
\hline \multirow[t]{3}{*}{$\begin{array}{l}\text { Concentration } \\
\text { (ppm) }\end{array}$} & \multicolumn{4}{|c|}{$\begin{array}{l}\text { Number of mosquito larvae from third instar Culex quinquifasciatus } \\
\text { which died each treatment ( } 20 \text { tails) }\end{array}$} \\
\hline & \multicolumn{4}{|c|}{\begin{tabular}{|l|l} 
Essential oil \\
\end{tabular}} \\
\hline & I & II & III & $\bar{x}$ \\
\hline 12,5 & 0 & 0 & 0 & 0 \\
\hline 25 & 2 & 1 & 1 & 1 \\
\hline 50 & 5 & 5 & 6 & 5 \\
\hline 100 & 10 & 11 & 12 & 11 \\
\hline 200 & 20 & 14 & 17 & 17 \\
\hline 300 & 20 & 20 & 20 & 20 \\
\hline 400 & 20 & 20 & 20 & 20 \\
\hline 500 & 20 & 20 & 20 & 20 \\
\hline 1000 & 20 & 20 & 20 & 20 \\
\hline K. + & 20 & 20 & 20 & 20 \\
\hline K. - & 0 & 0 & 0 & 0 \\
\hline
\end{tabular}

Description: Control $+=$ abate

Control - = tween 80

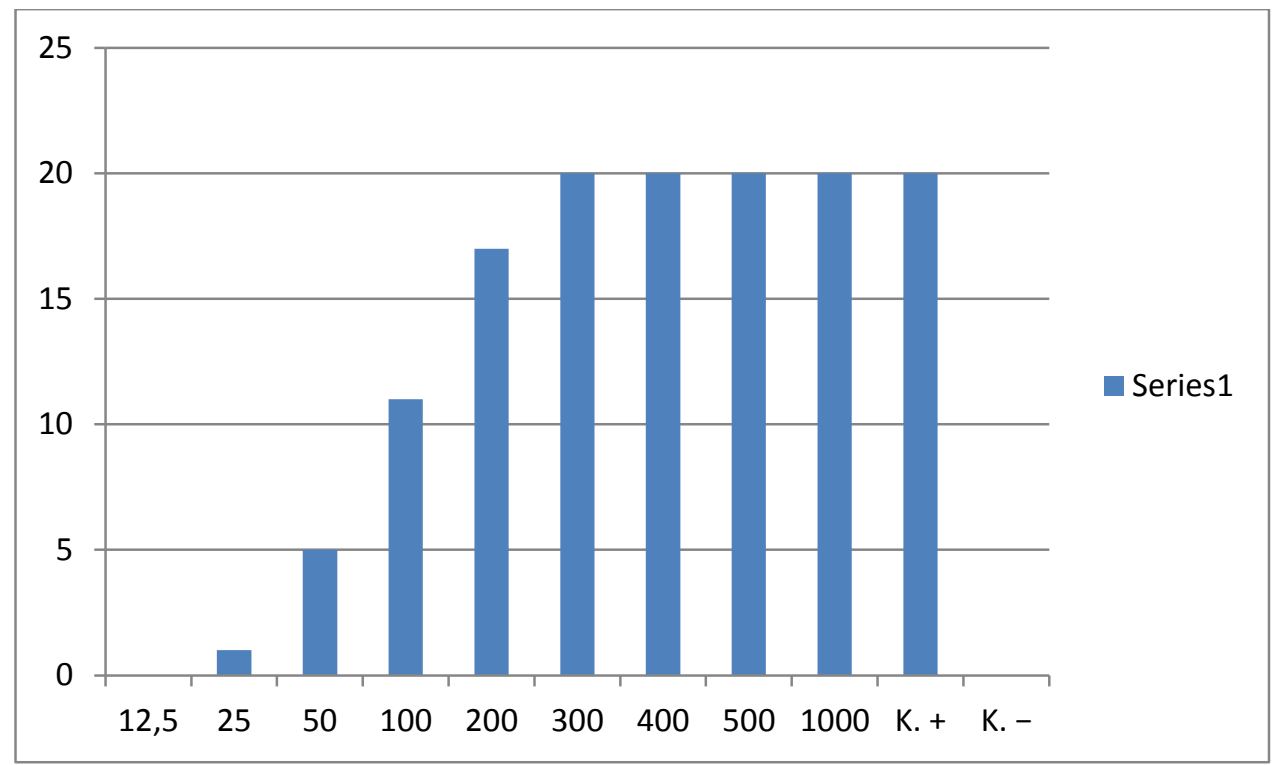

Figure 1. Graph of the relationship of the number of larval deaths per container with concentration 


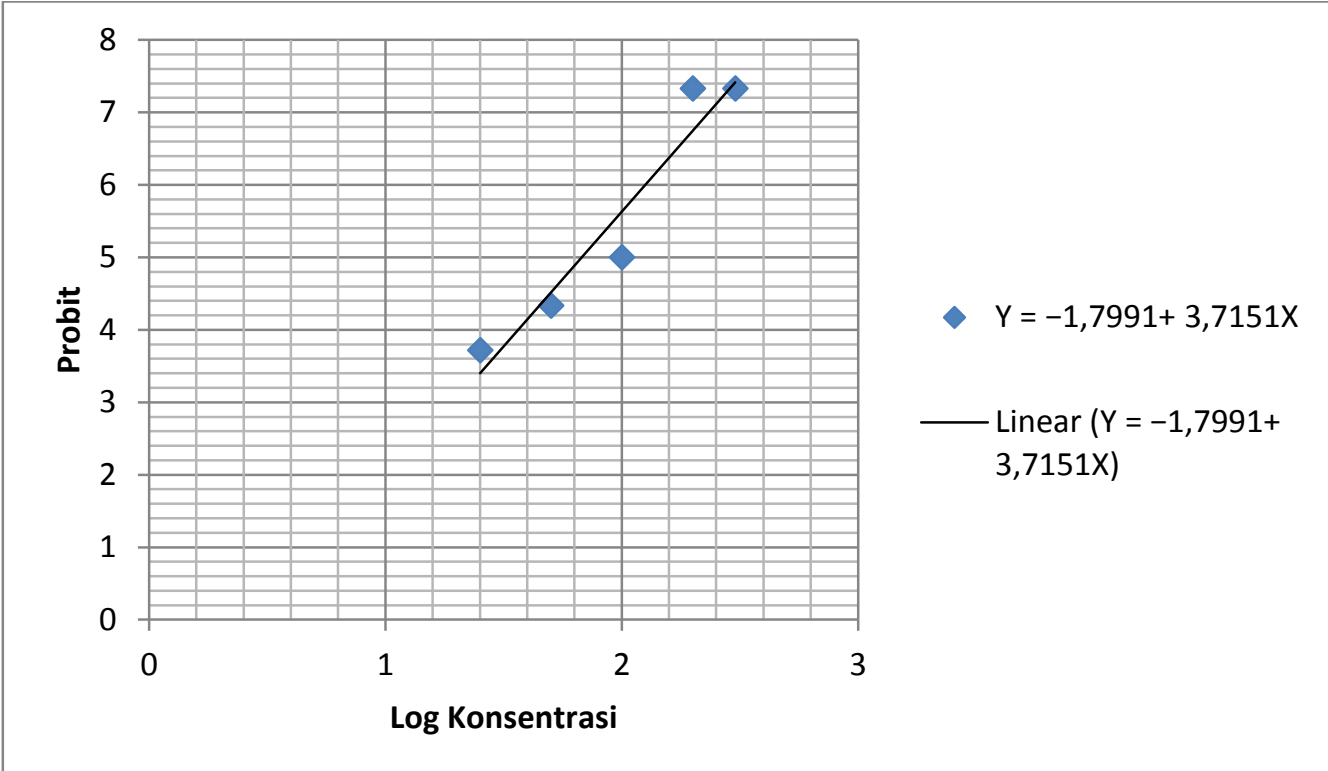

Figure 2. Graph of the relationship between log concentrations with probit essential oil for replication I

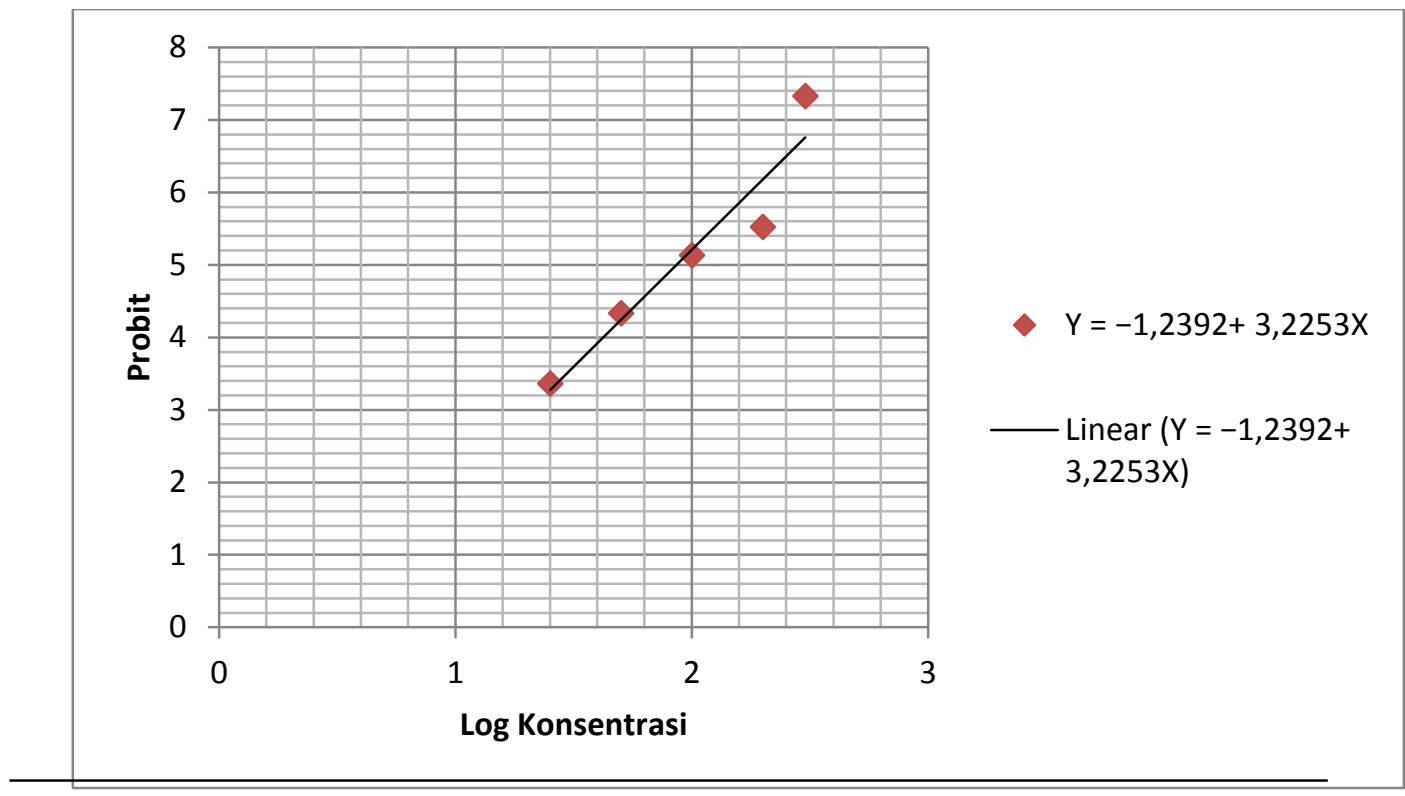

Figure 3. Graph of the relationship between log concentrations with probit essential oil for replication II 


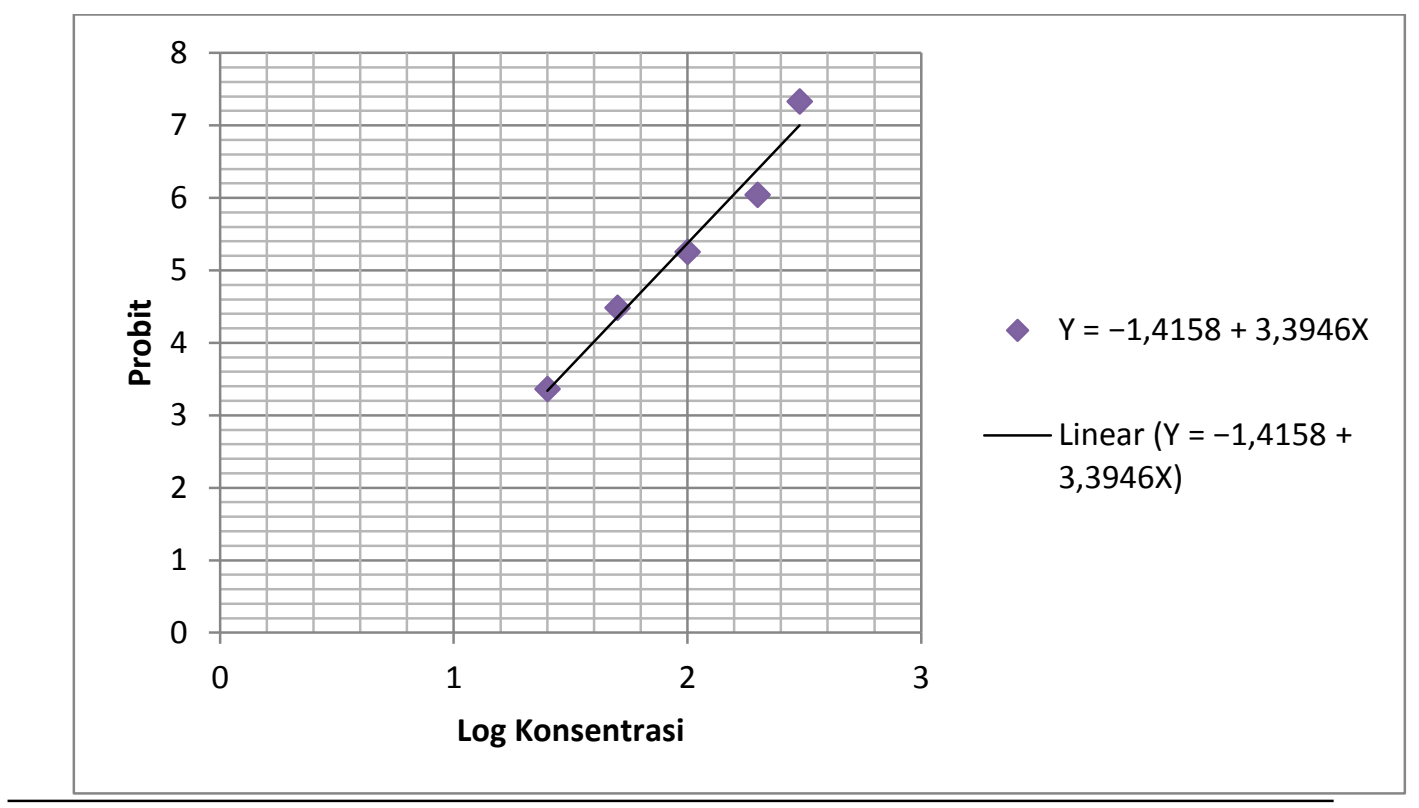

Figure 4. Graph of the relationship between $\log$ concentrations with probit essential oil for replication III 